\title{
L La "novela" de Artigas en el Manual de la Historia Argentina de Vicente Fidel López
}

\author{
Laura Sanchez \\ José Maristany'
}

J. Letourneau en su artículo "Le texte historique comme objet del a’nalyse littéraire" sostiene que el texto histórico, sin perder su especificidad, puede ser susceptible de un examen efectuado con las herramientas del análisis literarios y de la narratología. Tomando como base los conceptos de Paul Ricoeur, el autor afirma que el texto histórico se conforma en un "acto configuracional" o "puesta en intriga" en el que un conjunto de representaciones (abstractas o concretas) sigue un desarrollo secuencial constituido por un comienzo, una fase intermedia y un fin, estando los tres planos ligados lógicamente. La noción de "puesta en intriga" designa el modo de organización e interconexión de los elementos que entran en la representación de conjunto construida con argumentos o informaciones, por un autor. Es decir que, en forma argumentativa o narrativa, el texto parte de una escena inicial cuyo potencial trágico o retórico es desarrollado por la adición continua de elementos abstractos o concretos. Lo que se denomina habitualmente el plan de un texto es en realidad un guion o argumento seguido por el autor para elaborar su discurso en el marco de un diálogo imaginario con el lector, ya sea este percibido como un cómplice, un discípulo, una autoridad, un objetor o un adversario. Así pues, el poder persuasivo de un texto, su poder de veracidad relativa, se encarna y se expresa

1-Instituto Sup. del Profesorado "Joaquín V. González" - Universidad Nacional de La Pampa 
principalmente en el grado de seducción que logra el autor en su relación dialógica con el lector (142). Estos conceptos son especialmente aplicables al Manual de la Historia Argentina escrito por Vicente Fidel López y publicado en Buenos Aires en 1896.

El texto de López, dedicado a los profesores y maestros que la enseñan, sintetiza su obra mayor: la Historia de la República Argentina, su origen, su evolución y su desarrollo político hasta 1852, escrita entre 1883 y 1893 en diez volúmenes. El Manual se reeditó hasta mediados del siglo XX y en él "las jóvenes normalistas argentinas leerán y repetirán, una y otra vez, las lecciones en que se condensa cada momento del drama argentino. Y serán esas maestras, formadas en gran medida por López, las portadoras de un saber sobre la historia que modelarán, generación tras generación, la conciencia histórica de una masa creciente de niños y jóvenes a los que alcanza la escolarización" (SuárezSaab, 2).

Examinar este texto, resulta pues una vía regia para acceder a la conformación de la conciencia histórica de sucesivas generaciones, conciencia en la que operan las "ficciones orientadoras"-guiding fictions- que durante el siglo XIX guiaron la construcción de una imagen colectiva de la nación Argentina, de su pueblo, de su pasado y de su futuro ${ }^{2}$. Estas ficciones y los paradigmas retóricos que implantan, siguieron modelando, durante este siglo y en un proceso de "larga duración", toda una serie de discursos sobre la identidad y la historia nacionales.

Por su concepción de la escritura historiográfica y su maestría como narrador -López fue autor de relatos y novelas históricas- el Manual provocó una tremenda seducción sobre sus lectores. Suarez y Saab (1998) estiman que las razones del interés de los lectores tiene que ver menos con una exigencia de objetividad que de competencia evocativa. Las inexactitudes del Manual no disminuyen el interés por un relato bien contado, en el que el narrador se compromete y toma partido sin pretensiones de imparcialidad. El mismo López pareciera deplorar una cierta división del trabajo discursivo que lleva a separar las técnicas de la novela histórica de la escritura propiamente historiográfica:

Hacer que el pasado viva como el presente, aproximar lo lejano, colocarnos en la intimidad de los hombres importantes, o sobre una eminencia de donde se domine un vasto campo de batalla; dar la realidad de la carne y de la sangre a

2-Cf. Nicolas Shumway, La invención de la Argentina, Buenos Aires, Emecé, 1993."Las ficciones orientadoras de las naciones no pueden ser probadas, $y$ en realidad suelen ser creaciones tan artificiales como las creaciones literarias. Pero son necesarias para darle a los individuos un sentimiento de nación, comunidad, identidad colectiva y un destino común nacional" (p. 13) 
los personajes históricos que pudieran presentarse como personificaciones ideales y alegóricas de la leyenda; (...) todas estas peculiaridades del dominio del historiador han ido a parar a manos de la novela histórica. (...) Una cosa son los sucesos en sí mismos y otra es el arte de representarlos en la vida con todo el interés y con toda la animación del drama que ejecutaron. ${ }^{3}$

En las páginas que siguen trataremos de examinar el modo en que López construye en su Manual la figura de Artigas, personaje central en la segunda parte de su relato de la historia nacional, correspondiente al período de la Independencia. Este análisis nos permitirá poner en evidencia los rasgos peculiares de su escritura historiográfica, percibir la manera en que el pasado es construido, sus relaciones con el presente de la enunciación y las diferentes relaciones intertextuales e interdiscursivas que hacia el pasado y el futuro el texto pone en funcionamiento, como un eslabón privilegiado en la transmisión de las ficciones orientadoras que se impusieron en el imaginario nacional.

El objetivo será captar en el texto histórico, entre los enunciados científicos ${ }^{4}$, las configuraciones narrativas y dramáticas del relato, así como su intriga. Examinar de qué manera el personaje de Artigas es presentado, caracterizado y mediante qué concurso de circunstancias y cómo, aún utilizando elementos biográficos indiscutibles, es recreado, por López, como figura arquetípica, portadora de normas y sujeto ficticio encarnando el orden y la lógica del relato.

\section{Los caudillos en la historiografía rioplatense}

La cuestión de los liderazgos políticos en el siglo XIX, es un viejo problema que ha sido simplificado bajo el polisémico concepto de "caudillismo". Nuevas discusiones teóricas y el análisis de nuevas fuentes han puesto en duda muchos de los supuestos en que se basaba la construcción clásica del caudillismo.

Si bien este concepto evoca una amplia gama de sentidos y asociaciones, desde su construcción original en el Facundo de Sarmiento, la figura del caudillo ha sido utilizada tanto por historiadores o escritores, con planteos ideológicos diferentes, quienes abordaron esta cuestión buscando respuestas a temas que siguen estando vigentes como la problemática de la formación del Estado Nación.

3-Piccirilli,Ricardo, Los López. Una dinastía intelectual. Buenos Aires, EUDEBA, 1972. Citado por Suárez y Saab, op. cit.

4-El texto histórico es una composición en la cual entra un número importante de enunciados científicos (un enunciado es científico porque excluye la posibilidad de que su negación pueda ser igualmente verdadera), que se combinan con enunciados de otra naturaleza. En el proceso de textualización se opera la transformación del enunciado científico en argumento o en elemento narrativo.(Cfr. Letourneau, 135). 
Las nuevas perspectivas cuestionan que los caudillos hayan sustentado su poder en las relaciones clientelísticas dentro de la estancia. Por el contrario, plantean que las relaciones que se establecieron fueron mucho más complejas. Además, se comienza a pensar en el caudillismo como un sistema mucho más estable que la imagen presentada en los efoques tradicionales. (GoldmanSalvatore, 1998)

En Vicente Fidel López, integrante de la generación romántica y otro de los fundadores de la historiografía argentina, no habrá consideraciones para con los caudillos. López y Mitre coinciden en cuanto al origen pero difieren en la valoración que hacen de este fenómeno político posindependendiente. Para López, un porteñista acérrimo, el caudillismo era pura negatividad. Los conflictos sociales habían desatado un estado de barbarie, desorganización social y criminalidad que era imposible de solucionar. No intentaba integrar a los diferentes actores regionales en la interpretación del proceso independentista como sí lo hacía Mitre, para quien el caudillismo representaba la expresión de sentimientos democráticos que, canalizados y controlados por las instituciones republicanas, podían contribuir positivamente a la formación de la nación.

Las ideas que expresó López en su Manual de la Historia Argentina, publicado a fines del siglo XIX, están presentes también en otros manuales escolares de la época, lo cual demuestra la difusión que adquirieron los juicios vertidos en torno de los caudillos y las imágenes de "malos" y "villanos" de la historia.

La obra de López por su difusión en el aparato escolar y su vigencia de casi medio siglo, ayudó de manera significativa a configurar una tradición que establecía una clara diferencia entre los héroes de la revolución y los caudillos de la etapa posterior a la independencia, asociados estos últimos, a la anarquía posrrevolucionaria y a las informales organizaciones militares de las provincias.

A pesar de los constantes cambios en sus sentidos y usos, el caudillismo conservó muchos de los atributos clásicos ofrecidos por las interpretaciones de Sarmiento, Alberdi, Mitre y López.

\section{La "novela" de Artigas}

Lo que denominamos "la novela de Artigas" se desarrolla de manera intermitente en la segunda parte del Manual de Vicente Fidel López, entre las lecciones № 4 y № 35 . Una treintena de parágrafos debidamente titulados conforma el cuerpo de la "novela" que tiene como protagonista al caudillo de la

5-En este sentido, se pueden mencionar los Manuales de Juana Manso de Noronha de 1862; Nicanor Larrain, de 1883; Benigno T. Martínez, de 1885 y José Manuel Estrada de 1898. Todos estos, mencionados en Buchbinder, 1998. 
Banda Oriental. El relato avanza imbricado con otras historias, aquellas que relatan los otros frentes realistas que tuvo que sofocar la Revolución de Mayo. Artigas aparece como actor privilegiado en un drama histórico que el autor se encarga de transmitir con todo el colorido y las estrategias retóricas que pudieran cautivar al lector, al modo de las mejores novelas de aventuras.

Al retratar a Artigas y describir sus acciones, López hace un magnífico despliegue retórico propio del novelista que fue. Como ya lo dijimos antes, para nuestro autor la escritura de la historia no se encontraba divorciada de la prosa ficcional, sino que por el contrario ésta era el soporte necesario para hacer revivir el pasado en el discurso.

Lo primero que llama la atención al examinar la "novela", es el ensañamiento de López hacia la figura de Artigas y el lugar central que le concede como antihéroe en todos los sucesos que se desarrollan en la década que va desde la constitución de la Primera Junta de Gobierno en 1810 hasta la derrota del Oriental en Tacuarembó y su obligado exilio en Paraguay.

El principio de construcción del relato es la activación de un antagonismo entre Artigas y el gobierno porteño, por lo tanto de un nivel de intriga (Letourneau, 141), que adquiere su plena dimensión significante en la medida en que se inscribe de modo coherente en el universo simbólico de la comunidad nacional. López utiliza para diseñar este personaje la batería de recursos retóricos que la literatura y la historiografía liberal habían acumulado para crear el arquetipo en el que encarnaba la barbarie, esto es, el caudillo. Allí confluyen El matadero de Echeverría, Amalia de Mármol, el Facundo de Sarmiento y toda la constelación de discursos que desde la perspectiva unitaria y letrada describían a figuras como Ramírez, López y por supuesto, a Juan Manuel de Rosas, el gran tirano.

Esto tal vez no sería sorprendente, sino tal vez indicativo de la porosidad del discurso historiográfico para absorber ideologemas y paradigmas retóricos que atraviesan otros sectores discursivos, sobre todo aquellos de la literatura, el ensayo y el periodismo. Lo que sí llama la atención es el desplazamiento que se ha producido hacia la figura de Artigas, y lo que es más, la condensación en su persona de todos los "gérmenes morales" del caudillo, su presentación como el "huevo de la serpiente" de lo que sería luego, la "tiranía vitalicia" de Rosas.

\section{Artigas: "el gaucho malo"}

Célebre y perdurable es la descripción antropológica de los habitantes de las pampas que Sarmiento incluye en el Facundo. Allí se retratan cuatro tipos característicos: el rastreador, el baqueano, el gaucho malo y el cantor. Al 
referirse a Artigas, en el capítulo IV de la primera parte, si bien lo emparenta con la barbarie, Sarmiento dirá que el carácter e instintos del caudillo oriental eran los del baqueano, apto para ser comandante de campaña por su extraordinario conocimiento de la región en la que habita (60). Por su parte, Facundo condensa los rasgos del gaucho malo:"(...)un outlaw, un squatter, un misántropo particular (...) Hombre divorciado con la sociedad, proscrito por las leyes (...) salvaje de color blanco" (48).

López en su Manual, dotará a Artigas con todas las características morales y sociales del gaucho malo, según el retrato arquetípico que fijó Sarmiento en la figura de Facundo. Artigas inaugura la galería de malvados en la historia argentina del siglo XIX. La "novela" que lo tiene como protagonista es la historia de un traidor, que no tuvo reparos en utilizar todos los medios para alcanzar sus ambiciones personales. Todos sus actos son juzgados sobre el fondo de los supremos intereses "nacionales" de la Revolución de Mayo, que animaba a una elite de gentes "honorables y cultas". Al personalismo del caudillo, y su falta de escrúpulos morales, se contraponen los sagrados designios de la elite porteña.

Pero veamos ahora la manera en que se introduce al protagonista de esta historia pues en esa presentación está contenido el retrato moral del personaje que para López prefigura lógicamente sus conductas posteriores. Aquí el determinismo de factores familiares y ambientales, como en todos los personajes de su historia, es evidente. La maldad o la virtud exhibida por los personajes es esperable según se desprende de los retratos que sirven para su presentación. El parágrafo 5 de la lección no 4 presenta a Artigas de la siguiente manera:

Fue Artigas en sus principios un muchacho indómito y vicioso de Montevideo, nacido en una familia decente y honesta, aunque de poca fortuna, que huyó muy pronto del hogar: y que vagando por la selvática y solitaria campaña en compañía de malas gentes y de vagos, á favor de un genio astuto y pérfido, de cierta iniciación primaria en letras y experiencia, logró superar entre sus compañeros habituales y hacerse jefe o caudillo de los contrabandistas que merodeaban y defraudaban al fisco colonial entre las fronteras portuguesas y campos uruguayos de la Banda Oriental, de Entrerríos y Corrientes, donde pronto adquirió un nombre temible por las fechorías y felonías de todo género con que lo repetían por esas soledades. El primer impulso de este famoso matrero fue el de campear con los realistas contra "los porteños". A eso lo inducían los odios contrarios en su vida de contrabandista contra la Capital de donde procedían naturalmente las órdenes y las partidas policiales del fisco que lo perseguían. Le pareció además que haciéndose realista, en un momento en que los realistas necesitaban caudillo de esas campañas que ellos no podían dominar con sus 
tropas, lograría hacerse necesario y obrar á su antojo como jefe supremo de las soledades donde tenía su reino. Pero como era hombre de desorden y padrino de facinerosos, muy pronto tuvo un conflicto con el brigadier español Muesas, á causa de un robo de artículos de plata que uno de sus capitanejos había perpetrado en el campamento que el dicho brigadier tenía cerca de la Colonia. Artigas se insolentó, hizo fugar al delincuente, y sabiendo que el brigadier Muesas había dado orden de prenderlo, tomó caballos con otros muchos de los suyos, y se fugó, presentándose en Buenos Aires como patriota, y pidiendo servicio en las tropas que la Junta se disponía á mandar en apoyo del comandante Benavídez.

Este es el retrato con el que López presenta a Artigas en su Manual. En él están contenidos todos los atributos morales que permiten explicar la conducta posterior del personaje y convierten en previsibles todas sus acciones: indómito y vicioso, genio astuto y pérfido, matrero, hombre de desorden y padrino de fascinerosos, cachafaz de la peor clase. Además el cuadro presenta a un hombre acomodaticio y mercenario que cambia de jefes según se presenten las circunstancias. Ajeno a los ideales de la Revolución, busca amparo en Buenos Aires, escapando a la autoridad española que lo busca a raíz del robo de uno de sus subordinados.

Los rasgos del "gaucho malo" están contenidos en este retrato. La fama del personaje es un elemento importante: "pronto adquirió un nombre temible por las fechorías y felonías de todo género con que lo repetían por esas soledades". Sarmiento destacaba también este proceso de transformación del "gaucho malo" en materia legendaria: "su nombre es temido, pronunciado en voz baja (...) Los poetas de los alrededores agregan esta nueva hazaña (la espectacular huida de la partida que lo persigue) a la biografía del héroe del desierto, y su nombre vuela por toda la vasta campañan"(48). A la actuación político-militar se agrega una "prehistoria" que incluye no solamente los orígenes familiares y étnicos del personaje, sino también sus primeras hazañas en un ámbito acotado entre lo público y lo privado, y en las que despuntan ya las condiciones morales. Esa prehistoria desarrollada extensamente en el capítulo dedicado a la infancia y juventud de Facundo, es resumida por López en el parágrafo que acabamos de leer. Allí podríamos decir que termina "la vida privada de Artigas", como dice Sarmiento refiriéndose a su personaje en el capítulo mencionado, entendiendo por "privada" aquella esfera de la vida que el historiador dejaría de lado por ser difícilmente documentable y menos significativa en el encadenamiento de los acontecimientos políticos. Sin embargo, López no desdeña los datos de esta "vida privada" y por el contrario, cifra en ellos todo lo que vendrá luego. 
Por otra parte, converge en este retrato la obligada descripción de la naturaleza que acompaña y determina el carácter del caudillo. En el modelo retórico que se impone para describir al caudillo, la naturaleza humana se articula necesariamente con la naturaleza geográfica y esta última aporta un primer grado de explicación al fenómeno de la barbarie. Si bien Artigas nació en Montevideo, huyó muy pronto del hogar y se dedicó a vagar por "la selvática y solitaria campaña", las "soledades donde tenía su reino". El retrato moral se complementa con la descripción del espacio físico: una naturaleza que es percibida como puro caos e inmanejable como el mismo personaje, igualmente "indómita": "Las selvas espesas y sombrías, bajo cuyo follage se escondían ríos y arroyos innumerables" (452) dificultaban la vida sedentaria y facilitaban la vida vagabunda; esas eran las "guaridas de Artigas y de las hordas litoraleñas". En ese ámbito, así como Facundo devino en "el tigre de los llanos", Artigas se convertirá también en un felino al final de la novela, un jaguar en este caso. Un poco más adelante, al relatar las actitudes de Artigas y Rondeau frente a los hombres enviados por Buenos Aires para controlar la situación de la Banda Oriental y en especial para dominar al caudillo, se completa el retrato de éste último con referencias a su carácter felino:

Tenía el ojo penetrante, rastrero, recóndito de las razas felinas, que dilatando la pupila, ven lo negro de las tinieblas. Pero como ellas, era también huraño; y la falta absoluta de idealidad, de fantasía para levantar lo malo, lo perverso, a las esferas elevadas de la política, lo achataban hasta las condiciones de un malvado vulgar, travieso, si se quiere, pero sin ninguna de las condiciones que constituyen la perversidad heroica de los grandes caudillos, como Bolívar por ejemplo. (413)

La animalización del personaje y su identificación con un felino permite llevar a este enfrentamiento, en particular, y a la historia patria desde la Revolución de Mayo, en general, fuera de la lucha de intereses y de ideologías, expulsarla del mero ámbito de la conflictividad socio-cultural, para transformarla en una nueva etapa del dominio de la razón sobre la naturaleza. La razón encarnada en la elite culta y liberal de Buenos Aires, frente a la naturaleza de la que participa no solamente la campaña como espacio físico, sino también su fauna que comprendía tanto los "ganados y las caballadas innumerables" (452) como el "gauchaje indómito" y las tribus de indios Char-huas, Huen-huas, Tapes, mestizos, y los jefes de esta "horda melenuda, desnuda y harapienta" (453), es decir, los caudillos.

López explota en estos pasajes todos los lugares comunes que en distintas prácticas discursivas fueron definiendo a los caudillos. Su relato se construye 
con retazos de todos aquellos discursos que conformaron la ficción orientadora liberal. El texto histórico se articula y contamina con otros textos y discursos a través de los cuales ha cristalizado una manera de contar el pasado que es al mismo tiempo novedosa y conocida. Si la novedad de López consiste en poner en el origen del drama histórico que relata a Artigas, su estrategia narrativa recurre una y otra vez al arsenal de figuras y estereotipos que circularon en los sectores letrados para describir al Otro, indómito y misterioso. Esa "identidad narrativa" como la llamaría Ricoeur, se construye con materiales pre-fabricados, materiales discursivos altamente codificados y que llevaban varias décadas de cirulación social.

\section{La barbarie en movimiento}

Una vez que entramos en la "vida pública" de Artigas, en el momento en que la Junta de Buenos Aire le otorga el grado de teniente coronel, el relato toma cabalmente la forma de un duelo entre civilización y barbarie. El episodio inaugural que confirma lo que la "prehistoria" hacía prever, es lo que se conoce como "Exodo oriental"

arrancaron a la fuerza de los ranchos, aldeas y estancias, toda la población [...] mujeres, ancianos, niños sanos y enfermos. Hizo saquear y quemar las casas, destruir todo lo que no podía moverse hasta las aves caseras, y empujando por delante de sus hordas ese inmenso rebaño, castigando y degollando á los renitentes, aunque fueran mujeres, les empujó a la margen derecha del Uruguay y formó el Ayuy (¡de horrible recordación!) un campamento, toldería ó amasijo informe, monstruoso de entes humanos, desvalidos, débiles, postrados de miseria, y sin amparo contra el bárbaro y los sicarios que allí los comprimían como á bestias, para amarrar á su ley a los padres, á los maridos y á los hermanos que pudieran tener la más leve intención de escaparse ó de regresar al hogar. (394)

En primer lugar es importante destacar que López nunca nombra a este episodio como "éxodo", pues en ese caso se admitiría una voluntad colectiva de abandonar el territorio del Uruguay, con lo cual quedaría sin argumentos

6-En octubre de 1811 se firma el armisticio entre Montevideo y el gobierno de Buenos Aires por el que las tropas patriotas desocupan la Banda Oriental y queda el territorio bajo la autoridad española. Por su parte, el gobierno de Montevideo levantó el bloqueo y solicitó a los portugueses que se retiraran. Artigas, opuesto al pacto, emprendió la retirada de sus tropas seguido por gran parte de la población dejando tras de sí un territorio arrasado para que no pudiera ser usado por el enemigo. Este episodio, conocido como el Éxodo Oriental, consolidó el liderazgo de Artigas que instala su campamento en las márgenes del río Uruguay. 
para describir la escena en términos tan violentos como lo hace. López desea borrar todo indicio de voluntad popular que pudiera haber precipitado a la población de la Banda Oriental a abandonar sus tierras y pasar a la costa oeste del Uruguay, como asimismo intenta negar todo liderazgo de Artigas sobre el pueblo. El Ayui se describe como una "toldería", esto es, como el asentamiento típico de los indios y en el parágrafo siguiente habla de "malones" para referirse a las partidas de Artigas que recorrían los campos orientales.

La línea que separa a la civilización de la barbarie está perfectamente delimitada. Las partidas de Artigas están "al mando de foragidos como el negro Casavalle, como José Culta, el mulato Encarnación, el cabo Gay, el indio Amicho, y otros que formaban su Estado Mayor General" (394, subrayado en el original). Es evidente la ironía de López al subrayar de este modo la conformación del ejército de Artigas, en el que participaban todos aquellos sectores, campesinos, negros, indios, mulatos, que en la visión del autor no podían ser ciudadanos de la nueva nación.

El avance de la barbarie continúa con el predominio de Artigas sobre Entrerríos y Corrientes. En dos parágrafos se describen asesinatos y martirios ejecutados por las tropas del caudillo: un anciano muere "enchalecado" luego de serle interceptada una carta que le enviaba un amigo de Buenos Aires y un joven soldado correntino, hecho prisionero bajo capitulación es decapitado luego de pasar varios días amarrado con una cadena. (469).

En un tercer momento y durante el predominio de Artigas sobre Entre Ríos, las condiciones del campamento de Ayuí -luego del éxodo- se han extendido a toda la provincia y el avance de la barbarie es pintado en términos dramáticos, mostrando López un gran dominio en el arte de sugerir:

"La Democracia Federal de Artigas había reducido la vida del litoral á algo mucho peor que la forma embrionaria de las tolderías ó aduares propios de la vida salvaje (...) Las mujeres no podían mostrarse: pocas eran las que tenían un pedazo de lienzo con que cubrirse. Los montoneros arrebataban cuanto podía servir para algo; y lo demás ya se podrá comprender lo que era. (560)

Se describe apenas una porción del cuadro de la vida miserable y degradada en estas tierras y el resto se carga a cuenta de la imaginación de los lectores.

Las descripciones de López se inscriben en la tradición histórico-literaria que instauró la ficción orientadora liberal para relatar las acciones de los caudillos. Un repertorio de imágenes y tópicos que atraviesa el discurso social desde El Matadero hasta "La fiesta del monstruo" el cuento que escribieron en colaboración Borges y Bioy Casares y en el que se alude a las movilizaciones populares bajo el peronismo, ya a mediados de este siglo. El discurso historio- 
gráfico está inmerso en esa red discursiva e incorpora en su "puesta en intriga" las representaciones que han ido tomando cuerpo y fijándose en el imaginario colectivo.

\section{La interdiscursividad prospectiva: los tópicos de la "ciudad invadi- da" y del "cuerpo enfermo"}

Por otra parte, el discurso de la historia, y en especial, los manuales escolares, como es el caso del texto que analizamos, producen efectos retóricoideológicos que permanecen de modo inercial en el imaginario.

En el texto de López, por ejemplo, aparece el tópico de la ciudad invadida. Luego de la batalla de Cepeda en que las tropas de Buenos Aires son derrotadas por los caudillo litoraleños, Ramírez y López, nuestro autor afirma que "se esperaba (en Buenos Aires) por momentos un saqueo a manos de cinco mil bárbaros desnudos, hambrientos y excitados por las pasiones bestiales que en estos casos empujan los instintos destructores de la fiera humana -que como multitud inorgánica es la más insaciable de las fieras conocidas." (585, subrayado en el original). Al esquema retórico de la invasión y la amenaza, que tiene su temprano origen en los malones que asediaban las ciudades y pueblos de la colonia, se suma en este caso la huella de la psicología y la sociología de cuño positivista que desde las útlimas décadas del siglo XIX aportaban sus herramientas conceptuales para dar respuestas científicas a los fenómenos socio-culturales que surgían en la ciudad moderna. Pero esos conceptos parecen ser aptos también para describir el pasado. Las "multitudes inorgánicas" de la cita anterior, denominación en la que resuena Ramos Mejía autor de "Las multitudes argentinas", van reemplazando a otros colectivos como las "hordas" o los "malones".

Un poco más adelante, en el parágrafo titulado "El refresco en el Cabildo", López se refiere a la celebración que tuvo lugar luego de la firma del Tratado del Pilar en el cabildo de Buenos Aires a donde llegaron Ramírez, López y Carreras con "numerosas escoltas de hombres desaliñados, vestido de bombachas y ponchos (...) Toda esta chusma ató los redomones en las verjas de la Pirámide, y subió al Cabildo de Mayo (...) Fácil es conjeturar la indignación y la ira del vecindario al verse reducido a soportar tamañas vergüenzas y humillaciones". (589). El tópico de la invasión de las hordas salvajes a la ciudad se reeditó con la inmigración y el episodio del refresco en el cabildo y la ira e indignación del vecindario tuvieron su repetición en los acontecimientos del 17 de octubre de 1945, oportunidad en que la chusma se refrescó pero no en el Cabildo sino en la fuente de la Plaza de Mayo.

López utiliza asimismo una metáfora organicista que tuvo larga vida en 
nuestra historia contemporánea. Dirá que Artigas iba a "dejar enfermo - (sabe Dios por cuánto tiempo)- el organismo social y político de los pueblos del Río de la Plata á una y otra banda" (454) La enfermedad del cuerpo social se convertirá en una metáfora utilizada una y otra vez ya sea para describir el efecto de la población inmigratoria o para justificar las intervenciones violentas y autoritarias de los militares en la vida institucional de la nación durante nuestro siglo. Para López, los caudillos que aparecieron posteriormente fueron una réplica de este primer modelo: "Los caudillejos provinciales, que surgieron como la espuma que fermentaba de la inmundicia artiguista, eran simplemente jefes de bandoleros que segregaban los territorios donde imperaban, a la manera de tribus (...) (554-555). Nuevamente, la aparición de los caudillos provinciales es asimilada a una contaminación biológica producida por la degradación moral que representó Artigas y estimulada por la aparición de "bandoleros" que el territorio daba como frutos silvestres.

\section{Argentinos, pero ¿desde cuándo y cómo?}

Nos detendremos ahora en otro aspecto de la construcción narrativa del Manual. Nos referimos a la manera en que aparece el término "argentino", y las referencias a un estado-nación definido. Hablar de "argentinos" en la década siguiente a la Revolución de Mayo, esto es entre 1810 y 1820 , resulta anacrónico pues el nombre de Argentina recién tendrá sanción oficial en 1826. El Uruguay o Banda Oriental como era conocida, formaba parte del Virreinato del Río de la Plata y hasta la década de 1820, siguió viéndose a sí mismo como una provincia más del conjunto Ilamado Provincias Unidas. En la década que siguió a la Independencia, los orientales, los litoraleños y los porteños se veían como "ciudadanos" de las Provincias Unidas del Río de la Plata, y no como uruguayos y argentinos. López pasa por alto estas circunstancias y traza el escenario de estas acciones en un ámbito nacional perfectamente definido que no era tal. Precisamente la organización política de la nación y el sistema de gobierno a adoptar, será el punto álgido y el origen de las guerras civiles que se extenderán hasta 1860. En López el proyecto nacional se confunde con el proyecto político de Buenos Aires, su idea de gobierno es centralista y elitista. Esto le permite descalificar a Artigas como un traidor a la patria. Así en el parágrafo 11 de la lección № XIII, que lleva el título de "La lección moral", López afirma lo siguiente: "Hemos querido una vez por todas, poner en manos de la juventud culta, con todos sus detalles y su filiación cronológica, los procederes de Artigas como argentino, desde 1810 á 1813" (427). Como acabamos de decir hablar de "argentino" durante esos años responde a una invención, pero 
una invención que será útil para consolidar los lazos de la comunidad que se imagina en los relatos de la historia. Artigas aparece como el traidor a la patria, el "bandido fuera de la ley común de las gentes, outlaw" (428) y no como el defensor de intereses federalistas que no podían ser aceptados por los porteños. La "argentinidad" se inscribe en una temporalidad que pierde sus orígenes y se vuelve tan "natural" como la raza o el género de las personas. Más adelante, López rechaza la idea de que Artigas fuera un promotor o defensor de la Independencia oriental: "(...) no era sino un caudillo argentino, alzado contra el gobierno nacional" (463, subrayado en el original).Y más adelante en el mismo parágrafo hablará de "bandolero argentino", con lo cual justifica los acuerdos que el gobierno de Buenos Aires hizo con el portugués para exterminar al caudillo oriental.

\section{El Yahuar y el Toro}

Finalmente la "novela" se cierra en un parágrafo en el que López exhibe sus dotes de narrador. "La lucha entre el Yahuar y el Toro", es el título de la gran escena final, el duelo entre Artigas y Ramírez, caudillo de Entrerríos. Esta es la escena de la derrota definitiva del caudillo oriental:

El toro bravío le da allí (en la Bajada) la gran cornada: una segunda en el Sauce de la Luna: otra en Mocoretá. El yahuar se atrinchera en Abalos, su límite entre la vida y la muerte. La otra fiera salta la trinchera y destripa al famoso Jefe Supremo y Protector de los Pueblos Libres...Allá va huyendo ahora a brincos desesperados y se asila en el Paraguay donde una Gorgona moderna condena á los que la miran á no ver más la luz; pugilato de tres bestias feroces en resumen ¡Artigas, Ramírez y Francia! (596).

Este es el brillante final de la "novela" de Artigas. La metamorfosis de los personajes ya es total y la lucha se ha trasladado completamente al reino animal. El malvado ha tenido su merecido, y ha sido derrotado por aquellos mismos a los que dio vida y defendió.

\section{La lección moral en Vicente Fidel López}

La "novela de Artigas" muestra desde el comienzo su relación con el presente en un discurso que no tiene pretensiones de imparcialidad y en el que dialoga con el lector involucrándolo, siguiendo al pie de la letra el guión preestablecido.

La figura de Artigas que va construyendo López como paradigma del caudi- 
Ilo, en el que se encarnan los vicios de la barbarie, es usada por el autor para advertir a las "jóvenes generaciones" de los peligros y amenazas que en el presente de la enunciación se presentan en el país. Los enemigos ya no son los caudillos, ahora son las nuevas "multitudes inorgánicas", los inmigrantes que traen las ideas anarquistas y socialistas.

Si bien el libro está dedicado "a los profesores y maestros que enseñan la historia", estos docentes son los que formarán a las nuevas generaciones de dirigentes, y por eso la permanente apelación a los alumnos, como los destinatarios de la lección moral que el Manual pretende transmitir. El personaje de Artigas es recreado como una figura arquetípica, que le sirve a López para ejemplificar "lo que no hay que hacer" y "el que no hay que ser". Pero también le sirve para ir armando el "gran relato nacional", para inventar la historia que le permitirá a las nuevas generaciones encontrar los lazos que las unan, ir conformando la identidad nacional aunque siempre en función de la ficción orientadora liberal.

La primera "lección moral" que extrae López del personaje de Artigas aparece en el parágrafo 6 de la Lección IV, es decir a continuación de la presentación del retrato del caudillo. En este texto, previene acerca del peligro que significa el no saber elegir bien las compañías y las consecuencias que trae el dejarse llevar por las primeras impresiones y las necesidades del momento:

“...Muchas veces sucede que los hombres, los partidos y las naciones, arrebatados por la necesidad de defenderse ó de ofender al enemigo, no se cuidan debidamente ni con delicadeza, de los medios que emplean; y esta es la ocasión de que los jóvenes que estudian este incidente reparen que siempre puede obrarse con buenos principios morales, y ser intransigentes con todo lo que es malo ó irregular aunque en el primer momento pueda parecer útil. El nombre de Artigas era indudablemente de influjo, cualquiera que fuese la bandera que tomase; pero por ser un cacahafaz de la peor clase, debió haberse visto con tiempo que más daño había de hacer como amigo que el que podía hacer como enemigo; debió habérsele rechazado. Nada se hubiera perdido, porque nada hizo por la patria; y se hubiera ganado en la moral, y la realidad de los hechos" (360).

Advierte a los jóvenes acerca de no dejarse encandilar con quien puede parecer útil en un primer momento pero que a la postre mostrará su verdadera cara. No se podía esperar otra cosa -según la perspectiva de López- de quien se había criado en las soledades de la campaña y por lo tanto tenía el destino predeterminado. Pero si pensamos en los interlocutores del autor en este párrafo, queda claro que está advirtiendo a los futuros gobernantes acerca de los peligros que caerán sobre el país si la dirigencia no obra con principios firmes 
y no se cuidan de los medios que utilizan para fines que pueden ser nobles.

No quedan dudas que los interlocutores privilegiados por López y a quienes dirige sus enseñanzas morales son los "jóvenes cultos", como lo expresa en el parágrafo 11 de la Lección XIII, bajo el título "La lección moral".

No escatima, en este pasaje, calificativos para Artigas, atribuyéndole caracteristicas propias de alguien que no está en su sano juicio y que se ha rebelado al orden impuesto por las leyes, es decir al orden impuesto por los porteños.

"Hemos querido, una vez por todas, poner en manos de la juventud culta, con todos sus detalles y su filiación cronológica, los procederes de Artigas como argentino desde 1810 a 1813. Quedan pues señalados y comprobados los hechos con que el criterio social y sano puede pronunciar su juicio. Lo que va á seguir no es ya otra cosa que una serie de atentados propios de una ira despecha$\mathrm{da}$, de una conciencia sin freno, de una alma demente, obcecada, y de una ferocidad personal que la psicología histórica señala como una degradación característica y fatal a que han sido arrastrados todos aquellos que renegando del orden social y de la religión de las leyes se envuelven en los delirios de la omnipotencia. Caen en la demencia, se convierten en monstruos -dejando poluta la historia de los pueblos donde han surgido..." (427-428).

Cuando es necesaria la revolución y los ciudadanos "cultos" se sirven de personajes temibles como Artigas, deben asumir la responsabilidad por la situación que generan en la sociedad. De hombres como los caudillos ya se sabe qué se puede esperar; pero insiste López en dejar sentado el precio que los hombres cultos deben pagar por actuar con negligencia -conducta inesperada en hombres de estas características-: el desaliento, la desmoralización y corrupción de los pueblos. Situación que -según López- vivió el país después de que la Junta aceptara irresponsablemente los servicios de Artigas y que para 1820 ya plantea como "el derrumbe". Permanentemente se va reiterando esta idea, dándole al lector un lugar importante en la narración, seduciéndolo y mostrando así el poder persuasivo de su relato.

Veamos, finalmente, cómo pone en juego el presente, asociando "la invasión de las hordas salvajes" sobre Buenos Aires después del triunfo de los caudillos en la batalla de Cepeda, con el peligro que acarrea la llegada de las masas de inmigrantes que ingresan al país hacia finales del siglo XIX, amenazando el orden impuesto.

"Se esperaba por momentos un saqueo a manos de cinco mil bárbaros desnudos, hambrientos y excitados por las pasiones bestiales que en estos casos empujan los instintos destructores de la fiera humana -que como multitud inorgánica es la más insaciable de las fieras conocidas: cosa que debe tener pre- 
sente la juventud, expuesta por exceso de liberalismo, á creer en las excelencias de las teorías democráticas que engendran las teorías subversivas del socialismo y del anarquismo contra las garantías del orden social." (585).

Esta vez la advertencia tiene otro tono, interpela a los jóvenes y queda claramente expuesto el temor de López a la subversión del orden social por parte de quienes se excedan en los planteos liberales y ven en el socialismo y anarquismo la posibilidad de luchar por una sociedad más justa. Se actualiza la idea de cuidar los medios que se utilizan para lograr fines útiles por las consecuencias que trae el no medir las secuelas de estos actos.

Va llevando López admirablemente la intriga también en lo que se refiere a dejar un mensaje a sus lectores. Y como no podía ser de otra manera, el mismo final de lo que hemos denominado "la novela de Artigas" es una gran lección: no sólo termina derrotado, sino que son sus propios seguidores, quienes profesaban sus mismas ideas y quienes fueron el producto de su prédica, los que lo dejaron malherido obligándolo a terminar sus días humillado, sin poder regresar a la Banda Oriental.

\section{A modo de conclusión}

A través de este recorrido hemos intentado demostrar de qué manera el Manual de Vicente F. López elabora discursivamente el pasado y cuál es su estrategia para que ese pasado sea ejemplar en el presente. Su escritura se encuentra atravesada y al mismo tiempo refuerza, no sólo el contenido de cierta "ficción orientadora" de Argentina, según la cual se decidió qué visión del pasado obtendría la legitimidad y se constituiría en la versión oficial; qué figuras serían elevadas al rango de héroes nacionales; qué relatos de valor y sacrificio serían retenidos y embellecidos para definir el alma argentina; qué rol ocuparían en la historia argentina las provincias y Buenos Aires, los gauchos, el pueblo, y los caudillos. No sólo entonces el contenido de esta ficción sino también los modos retóricos y la simbología que se impusieron para transmitir cierta imagen de la nación, son los que están estructurando la escritura histórica de López.

Por otra parte, la historia sirve tanto para conocer el pasado y explicarlo, como para orientar el futuro. Si López evoca la "sombra terrible" de Artigas y le otorga el rango de figura clave en la historia de la nación, desde la pura negatividad, no es menos cierto que esa "sombra terrible" y el esquema binario del que surge, acompaña el desarrollo histórico y se recarga de diferentes sentidos: ya en el Manual, a través de sus lecciones morales, se orienta hacia nuevos actores sociales que están desafiando la estabilidad y continuidad de la repúbli- 
ca oligárquica y reivindican una ciudadanía más plena. El significante de la barbarie seguirá vigente pero apuntará de ahora en más hacia otros significados. Así, en la década siguiente, mientras la elite dirigente invierta el sentido de palabras como gaucho y criollo para dotarse de una tradición que preserve y justifique sus aspiraciones a dirigir la nación, el lugar retórico e imaginario de las "hordas salvajes" lejos de desaparecer, será ocupado por aquellos sectores, principalmente de origen inmigratorio, que están configurando una nueva sociedad.

\section{Resúmen}

\section{La “novela" de Artigas en el Manual de la Historia Argentina de Vicente Fidel López}

El objetivo de este trabajo es analizar de qué manera Vicente Fidel López elabora lo que denominamos "la novela de Artigas" en su Manual de la Historia Argentina, dedicado a los profesores y maestros que la enseñan, cuya primera edición se publica en 1896. La obra historiográfica de López es una derivación de su labor literaria porque para él, la historia es, además de elaboración científica, capacidad de evocación, de actualización dramática que sólo puede ser expuesta con la sensibilidad de un artista. En el Manual, leído y transmitido por varias generaciones de jóvenes normalistas argentinas, nos interesa especialmente examinar el modo en que López construye retóricamente el personaje de Artigas como paradigma del caudillo en el que se encarnan todos los vicios de la barbarie, y asimismo la manera en que ese retrato es extrapolado al momento de la enunciación-escritura del texto, para advertir a las jóvenes generaciones de criollos sobre los nuevos enemigos de la Nación que hacia fines del siglo XIX, ya no eran los caudillos sino los socialistas y anarquistas que habían llegado al país con el flujo inmigratorio.

\section{Palabras claves}

$$
\text { - Historiografía - Caudillos - V.F.López - Narrativa - }
$$

\section{Abstract}

\section{The "novel" of Artigas in the Manual de la Historia Argentina, by Vicente Fidel Lopez}

The purpose of this work is to analyse the way in which Vicente Fidel Lopez frames what we call "the novel of Artigas" in his Manual de la Historia Argentina, dedicado a los profesores y maestros que la enseñan (Textbook of Argentine History, devot- 
ed to professors and teachers who teach it), whose first edition was published in 1896 . Lopez's historiographic work is a development from his literary activity, since -in his opinion- apart from being a scientific process, history implies an ability for evocation and dramatic re-creation that only an artist $[$ s sensitivity can put across. In the Manual, read and transmitted by several generations of argentine normalistas, we are specially interested in examining the manner in which Lopez rhetorically constructs Artigas' character as the paradigm of the caudillo (leader) in which all barbarie (barbarity) vices are incarnated; and also, the way in which this portrait is extrapolated at the moment of the enunciation-writing of the text, to warn young generations of criollos against the new enemies of the Nation that, by the late 19th century, were not the caudillos but socialists and anarchists who had arrived at the country with the migratory flow.

\section{Key words}

- historiography - caudillos - V.F.López - narrative

\section{Referencias Bibliográficas}

*BUCHBINDER, Pablo, "Caudillos y caudillismo: una perspectiva historiográfica". En Goldman-Salvatore (comps.) 1998, op. cit.

*FREGA, Ana "La virtud y el poder. La soberanía particular de los pueblos en el proyecto artiguista". En Goldman-Salvatore (comps.) 1998 op. cit.

*GOLDMAN-SALVATORE (comps.) Caudillismos Rioplatenses. Nuevas miradas a un viejo problema. EUDEBA, Bs. As., 1998.

*HALPERÍN DONGHI, Tulio, De la revolución de independencia a la confederación rosista, Paidós, Colección Historia Argentina, T. 3, Bs. As., 1980.

*LETOURNEAU, Jocelyn, "Le texte historique comme objet de l'analyse littéraire” en La recherche littéraire. Objets et méthodes, Claude Duchet y Stéphane Vachon (dir.), Montréal, XYZ., 1993.

*LÓPEZ, Vicente F., Manual de la Historia Argentina, Buenos Aires, A.V.López Editor, 1910.

*LUDMER, Josefina, El género gauchesco. Un tratado sobre la patria, Buenos Aires, Sudamericana, 1988.

*SARMIENTO, Domingo F., Facundo, Buenos Aires, Losada, 1971.

*SHUMWAY, Nicolás, La invención de la Argentina, Buenos Aires, Emecé, 1993. *SUÁREZ, Carlos y Jorge Saab, "La invención de López (El Manual de la Historia Argentina de Vicente Fidel López)"en Revista Clio \& Asociados. La historia enseñada, año III, 1998, Universidad Nacional del Litoral, Santa Fe, Argentina, pp. 62-74. 